\title{
A Study on Parametric Wave Estimation Based on Measured Ship Motions
}

\author{
Ulrik Dam NIELSEN* and Toshio ISEKI ${ }^{* *}$
}

\begin{abstract}
The paper studies parametric wave estimation based on the 'wave buoy analogy'. The ship motion data obtained from the training ship Shioji-maru are used for the estimation and the results are compared with estimates of the sea states obtained from other measurements and observations. Furthermore, the estimating characteristics of the parametric model are discussed by considering the results of a similar estimation concept based on Bayesian modelling. As a result, it is revealed that there is a distinct difference in the estimation of wave heights and wave periods. This is explained by referencing the concrete modelling procedure of the two approaches.
\end{abstract}

Keywords: Seakeeping, on-board wave estimation, full-scale ship motion measurements, parameterized wave spectra, nonlinear optimization

\section{Introduction}

Sea state parameters, or the directional wave power spectrum, around a ship are needed on a continuous basis for navigational and operational guidance to a ship's master. The likelihood of large wave-induced acceleration, for example, depends amongst others on the sea state in which the ship operates. Thus, if the sea state is estimated continuously it is possible to raise a warning if vessel speed and course is in a region where the wave-induced acceleration may become critical to, say, stowed containers on a container vessel. The evaluation of a vessel's performance ${ }^{(1)}$ requires also input of the sea state parameters, so onboard wave estimation is highly relevant for any type of monitoring and/or decision support system for safe and efficient navigation.

In the literature there are studies ${ }^{(2,3,4,5,6)}$ concerning the estimation of sea state parameters using measured ship responses (e.g. motion data) where the ship, to make an analogy, acts as a wave rider buoy and for this reason the methodology is called the 'wave buoy analogy'. The fundamental input to the wave buoy analogy is a set of response measurements where the individual response basically can be any one as long as a linear (complex-valued) transfer function may be associated with the response. The wave buoy analogy provides a robust alternative to wave radar by utilization of on-board response measurements that are often carried out irrespectively on many of today's navy and commercial vessels. Consequently, the wave buoy analogy is also a relatively inexpensive estimation concept, since the system development is associated with software only.

This study considers sea state estimation from fullscale motion measurements obtained during experiments with the training ship Shioji-maru of Tokyo University of Marine Science and Technology. In connection with the experiments wave measurements were made also using a wave radar monitoring system and, moreover, visual observations were carried out.

\section{Theory}

\subsection{Parametric model of wave spectrum}

The parameterized directional wave spectrum $E(\omega, \theta)$ is chosen to be a fifteen-parameter tri-modal spectrum

(1) that allows for the mixed sea such as wind waves and swell.

$$
\begin{aligned}
& E(\omega, \theta)=\sum_{i=1}^{3} E_{i}(\omega) \cdot G_{i}(\omega, \theta) \\
& E_{i}(\omega)=\frac{1}{4}\left(\frac{4 \lambda_{i}+1}{4} \omega_{p, i}^{4}\right)^{\lambda_{i}} \frac{H_{s, i}^{2}}{\Gamma\left(\lambda_{i}\right) \omega^{4 \lambda_{i}+1}} \\
& \times \exp \left[-\frac{4 \lambda_{i}+1}{4}\left(\frac{\omega_{p, i}}{\omega}\right)^{4}\right] \\
& G_{i}(\omega, \theta)=A\left(s_{i}\right) \cos ^{2 s_{i}}\left(\frac{\theta-\theta_{\text {mean }, i}}{2}\right) \\
& A(s)=\frac{2^{2 s-1} \Gamma^{2}(s+1)}{\pi \Gamma(2 s+1)}
\end{aligned}
$$


where $\omega$ and $\theta$ are the angular frequency of waves and the relative wave heading, respectively. $E_{i}(\omega)$ is a one dimensional wave spectrum with $\omega_{p}, H_{s, i}$ and $\lambda_{i}$ being the peak frequency, the significant wave height and the shape parameter, respectively, of the spectrum. $G_{i}(\omega, \theta)$ is the directional distribution function, where $\theta_{\text {mean }}$ is the mean relative wave direction. $A(\mathrm{~s})$ is a constant to secure normalization and evaluated using Gamma function of the spreading parameter $s$.

\subsection{Governing equation system}

The governing equation system of the wave buoy analogy originates from a linear assumption relating the response spectrum $S_{i j}\left(\omega_{e}\right)$ of the $i$ th and $j$ th responses to the directional wave spectrum $E\left(\omega_{e}, \theta\right)$

$S_{i j}\left(\omega_{e}\right)=\int_{-\pi}^{\pi} \Phi_{i}\left(\omega_{e}, \theta\right) \overline{\Phi_{j}\left(\omega_{e}, \theta\right)} E\left(\omega_{e}, \theta\right) d \theta$

$S_{i j}\left(\omega_{e}\right)$ is the measured cross spectrum whereas the right-hand side is the calculated cross spectrum using the estimated $E(\omega, \theta)$ and the response amplitude operators $\Phi\left(\omega_{e}, \theta\right)$ of the considered ship responses. The bar denotes the complex conjugate.

An optimization problem can be established by minimising the difference between the left- and the right-hand side of Eq. (2), with the wave spectrum $E(\omega, \theta)$ given by Eq. (1). Thus, the least squares method is applied and the nonlinear optimization can be solved directly using, e.g., MATLAB ${ }^{\circledR}$ by invoking "fmincon", which is a built-in function based on sequential quadratic programming. The implementation of the problem is, however, not straight forward due to the triple-valued function problem that must be taken into account for advancing ships ${ }^{(2)}$. Moreover, the present model considers an energy conservation requiring the $0^{\text {th }}$ order spectral moment of the left- and righthand side to be identical, leaving out details and further argumentation for reasons of space limitation ${ }^{(3)}$.

\section{Full-scale Motion Measurements}

Ship motion time histories were measured using the T.S. Shioji-maru of Tokyo University of Marine Science and Technology. A photo and principal particulars of the ship are shown in Table 1 and Figure 1, respectively. The experiments were carried out on July 25, 2007, January 23, 2008 and March 11, 2009. The location of the experimental area was off Nojima Cape in Chiba Prefecture, Japan.

The wave conditions of the experimental area were partially observed at Nojima Cape lighthouse using the wave monitoring radar system operated by the
Table 1 Principal particulars of T.S. Shioji-maru.

\begin{tabular}{|l|r|}
\hline Length, $L_{\mathrm{pp}}$ & $46.00 \mathrm{~m}$ \\
\hline Breadth, $B_{\mathrm{mld}}$ & $10.00 \mathrm{~m}$ \\
\hline Depth, $D_{\text {mld }}$ & $6.10 \mathrm{~m}$ \\
\hline Draught, $T_{\text {mld }}$ & $2.65 \mathrm{~m}$ \\
\hline Displacement & $659.4 \mathrm{t}$ \\
\hline
\end{tabular}

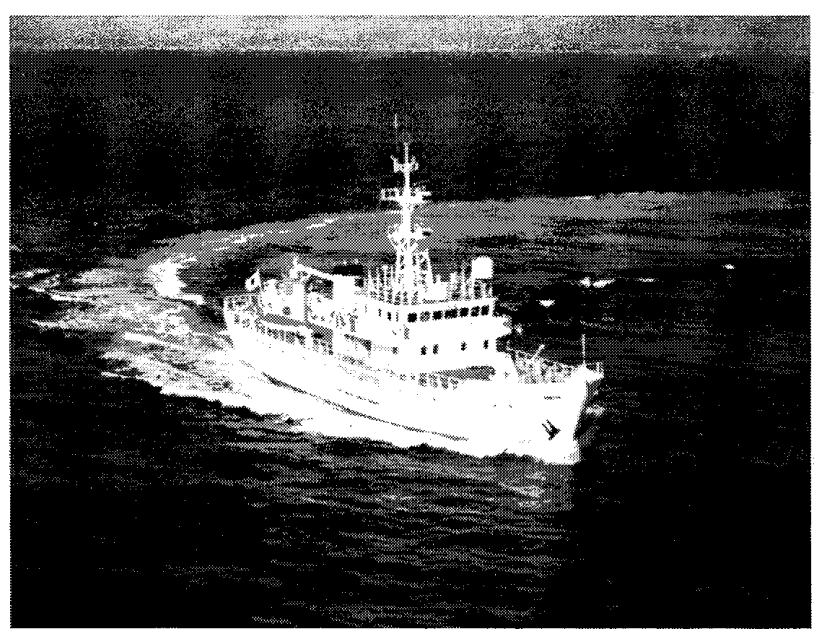

Fig. 1 Photography of T.S. Shioji-maru.

Third Regional Japan Coast Guard Headquarters.

Figure 2 shows the cover area which is the fanshaped region between 100 and 221.7 degrees and distance between 0.5 and 2 miles from Nojima lighthouse. The trajectories of the T.S. Shioji-maru are also indicated in the figure. To measure changes in ship motions with respect to the encounter angle of waves, the ship motions were recorded during 90-minute manoeuvres involving straight sections and changes in course.

Table 2 shows the operational conditions which include courses and mean speeds of the ship for each straight running, the directions and speeds of true wind and wave conditions measured by visual observations.

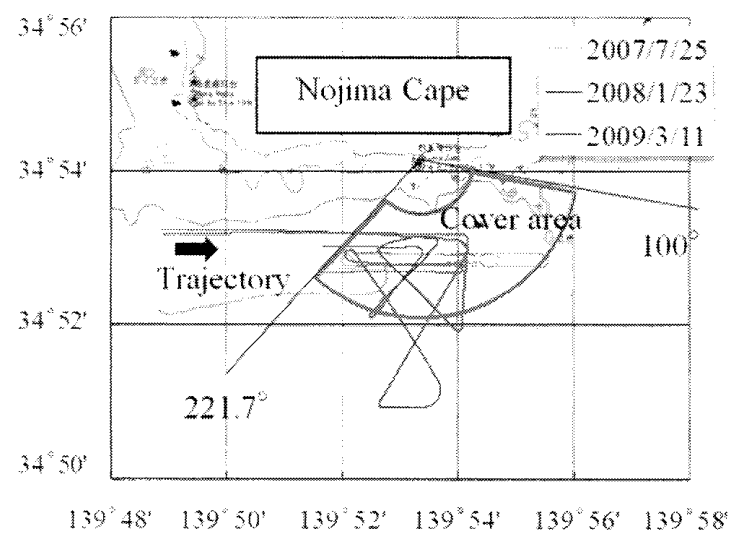

Fig. 2 Experimental area with ship trajectories. 
Table 2 Operational conditions.

\begin{tabular}{|l|c|c|c|c|c|c|}
\hline $\begin{array}{l}\text { Run } \\
\text { ID }\end{array}$ & $\begin{array}{l}\text { Vessel } \\
\text { course } \\
\text { [deg.] }\end{array}$ & $\begin{array}{l}\text { Vessel } \\
\text { speed } \\
\text { [kts] }\end{array}$ & $\begin{array}{l}\text { Wind } \\
\text { dir. } \\
\text { [deg.] }\end{array}$ & $\begin{array}{l}\text { Wind } \\
\text { speed } \\
\text { [m/s] }\end{array}$ & $\begin{array}{l}\text { Wave } \\
\text { dir. } \\
\text { [deg.] }\end{array}$ & $\begin{array}{l}\text { Wave } \\
\text { height } \\
\text { [m] }\end{array}$ \\
\hline A1 & 90 & 12 & 110 & 3 & 110 & 1.0 \\
\hline A2 & 270 & 12 & 110 & 4 & 110 & 1.0 \\
\hline A3 & 90 & 8 & 110 & 4 & 110 & 1.0 \\
\hline A4 & 270 & 8 & 110 & 4 & 110 & 1.0 \\
\hline \multicolumn{7}{|c|}{$(2008 / 01 / 23)$} \\
\hline B1 & 90 & 10 & 350 & 11 & 100 & 1.9 \\
\hline B2 & 210 & 10 & 0 & 9 & 100 & 1.9 \\
\hline B3 & 330 & 10 & 340 & 10 & 50 & 1.6 \\
\hline B4 & 90 & 8 & 340 & 11 & 50 & 1.6 \\
\hline B5 & 270 & 8 & 0 & 9 & 50 & 1.6 \\
\hline \multicolumn{7}{|c|}{$(2009 / 03 / 11)$} \\
\hline C1 & 90 & 10 & 350 & 5 & 70 & 1.2 \\
\hline C2 & 180 & 10 & 330 & 4 & 70 & 1.2 \\
\hline C3 & 315 & 10 & 0 & 4 & 90 & 1.0 \\
\hline C4 & 225 & 10 & 350 & 3 & 90 & 0.9 \\
\hline C5 & 45 & 10 & 350 & 2 & 190 & 0.8 \\
\hline C5 & 270 & 10 & 350 & 2 & 210 & 0.7 \\
\hline
\end{tabular}

The wave conditions observed by the wave monitoring radar system are summarized in Table 3 . The table shows also the wave data reported by the wave analysis of Japan Meteorological Agency (JMA). The JMA data in the table is indicating the wave parameters off the Boso Peninsula (lat. $35^{\circ} 20^{\prime} \mathrm{N}$, long. $\left.140^{\circ} 45^{\prime} \mathrm{E}\right)$. Therefore, discrepancy between the observations is probably a result of the land shape as shown in Figure 2. The sea area around Nojima Cape is in a shadow zone with respect to the NE waves. For this wave direction, it is, in principle, possible to compare the results of the parametric estimation to observed data of only the wave monitoring radar system in the cover area. When the T.S. Shioji-maru was navigating far off Nojima Cape on January 23, 2008, however, the wave direction was NE as reported by JMA.

Ship motions and the position were measured using a fiber optic gyro and its built-in GPS system (JCS7401GA, Japan Aviation Electronics Industry, Limited). Just for reference, the relative wave height was measured by a supersonic wave sensor (UH401, KENEK) installed at the bow. These data were sampled every $0.1 \mathrm{~s}$ and recorded in the hard disk of a notebook PC through the RS-232C port.

Figure 3 shows one of the measured set of time histories of pitch and roll angles and the vertical acceleration. The data was measured on January 23, 2008 and the total time span was 90 minutes. As shown in Figure 2, combination manoeuvres involving 12minute straight sections changed the encounter angle
Table 3 Measured wave parameters by wave radar monitoring system (Radar) and by Japan Meteorological Agency (JMA).

\begin{tabular}{|l|c|c|c|c|c|c|}
\hline \multirow{2}{*}{ Date } & \multicolumn{2}{|c|}{$\begin{array}{c}\text { Wave dir. } \\
\text { [deg.] }\end{array}$} & \multicolumn{2}{c|}{$\begin{array}{c}\text { Wave period } \\
\text { [sec.] }\end{array}$} & \multicolumn{2}{c|}{$\begin{array}{c}\text { Wave height } \\
{[\mathrm{m}]}\end{array}$} \\
\cline { 2 - 7 } & Radar & JMA & Radar & JMA & Radar & JMA \\
\hline $\begin{array}{l}2007 \\
07 / 25\end{array}$ & 137 & ESE & 11 & 10 & 1.0 & 0.6 \\
\hline $\begin{array}{l}2008 \\
01 / 23\end{array}$ & 120 & NE & 10 & 10 & 1.6 & 2.0 \\
\hline $\begin{array}{l}2009 \\
03 / 11\end{array}$ & 128 & E & 19 & 11 & 1.3 & 2.3 \\
\hline
\end{tabular}
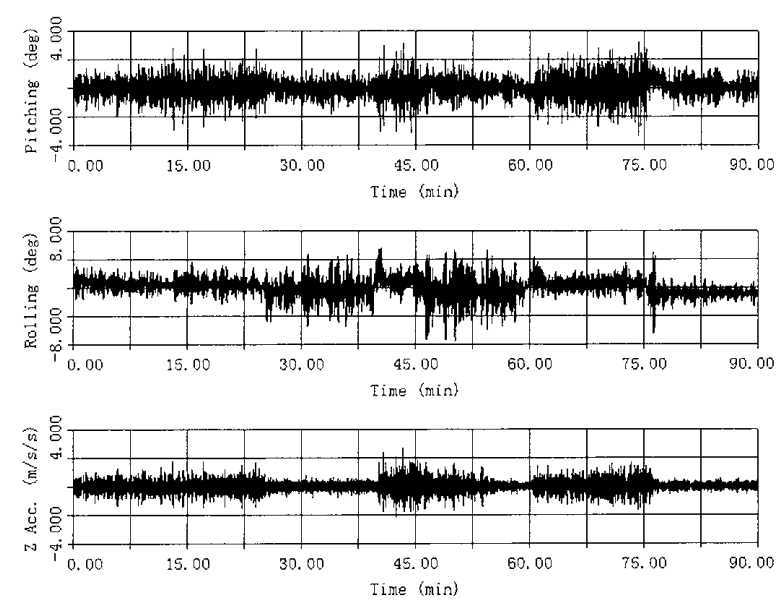

Fig. 3 Measured time history data of pitch angle, roll angle and vertical acceleration (Run ID B1-B5).

to waves and caused the change of amplitude of time histories. The beginnings of large amplitude pitching motions can be seen at 10 and 60 minutes, where the measurements likely relate to head sea conditions. This agrees well with the wave direction observed by the wave monitoring radar system at Nojima lighthouse. On the other hand, the beginning of a large amplitude rolling motion can be seen at 47 minutes in the measured time history. This was measured during offshore running with course of 330 degrees and can be considered as a result of direct encounter with the NE waves.

Figure 4 shows the results of the cross spectrum analysis of the data B1. The actual time histories correspond to the first 10 minutes of Figure 3. In this analysis, the MAR (Multivariate Auto Regressive) modelling procedure was used and the optimum order of the model was chosen by MAICE (Maximum Akaike's Information Criterion Estimation) method. The boldfaced solid lines and light-faced solid lines in the figure represent the real and imaginary part of the cross spectra, respectively. As mentioned above, the course of 90 degrees is in the head seas condition. 

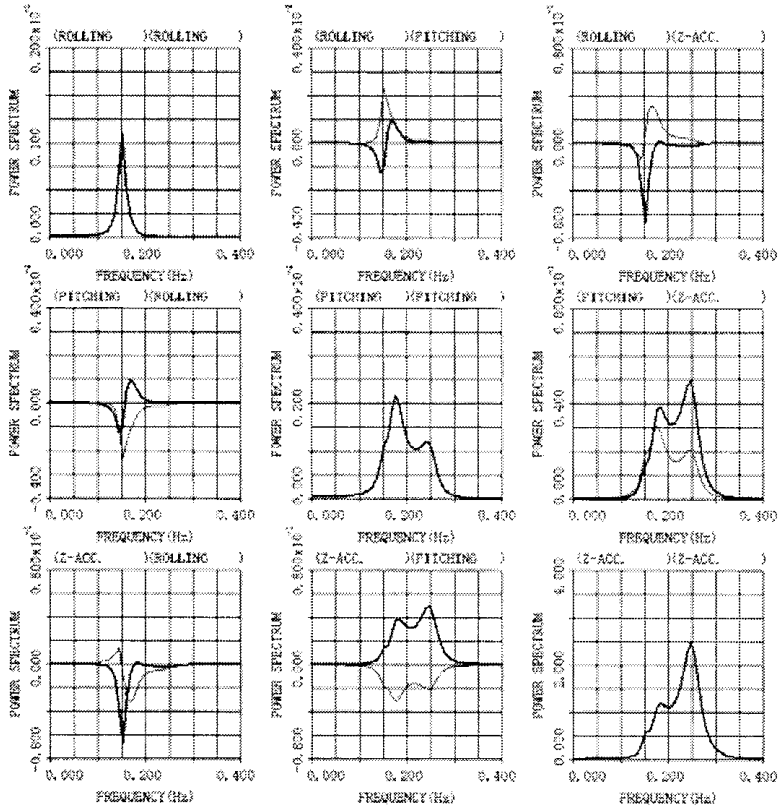

Fig. 4 Response spectra obtained by MAR modelling (Run ID B1).

Therefore, it can be seen that the spectra of pitching and vertical acceleration have rather wide feet.

\section{Parametric Wave Estimation}

\subsection{Results}

The analysis of the data has been conducted as a post-voyage process and the results of the parametric wave estimation are given in Figures 5-7 that show the significant wave height, the wave period and the absolute wave direction, respectively. The wave parameters were estimated using the data of pitch angle, roll angle and vertical acceleration. For the individual wave parameter, the measurements obtained from the visual observations, the wave radar monitoring system and JMA are also included. It should be noted that it is difficult to estimate the wave period from visual observation for which reason 'Visual observation' is not included in Figure 6. Moreover, it is not clear from the measurements by the wave radar monitoring system which characteristic wave period is considered. However, for the wave periods of JMA and the parametric model, the results are based on the mean period $T=m_{0} / m_{1}$, where $m_{0}$ and $m_{1}$ are the $0^{\text {th }}$ and $1^{\text {st }}$ order spectral moment, respectively. Finally, it is noteworthy that only one set of measurements have been obtained from the wave radar monitoring system and from JMA for each of the three experimental sets, $(\mathrm{A} 1, \ldots, \mathrm{A} 4),(\mathrm{B} 1, \ldots, \mathrm{B} 5)$ and $(\mathrm{C} 1, \ldots, \mathrm{C} 6)$, considered. This fact explains why the measurements behave as constants within the individual experi-
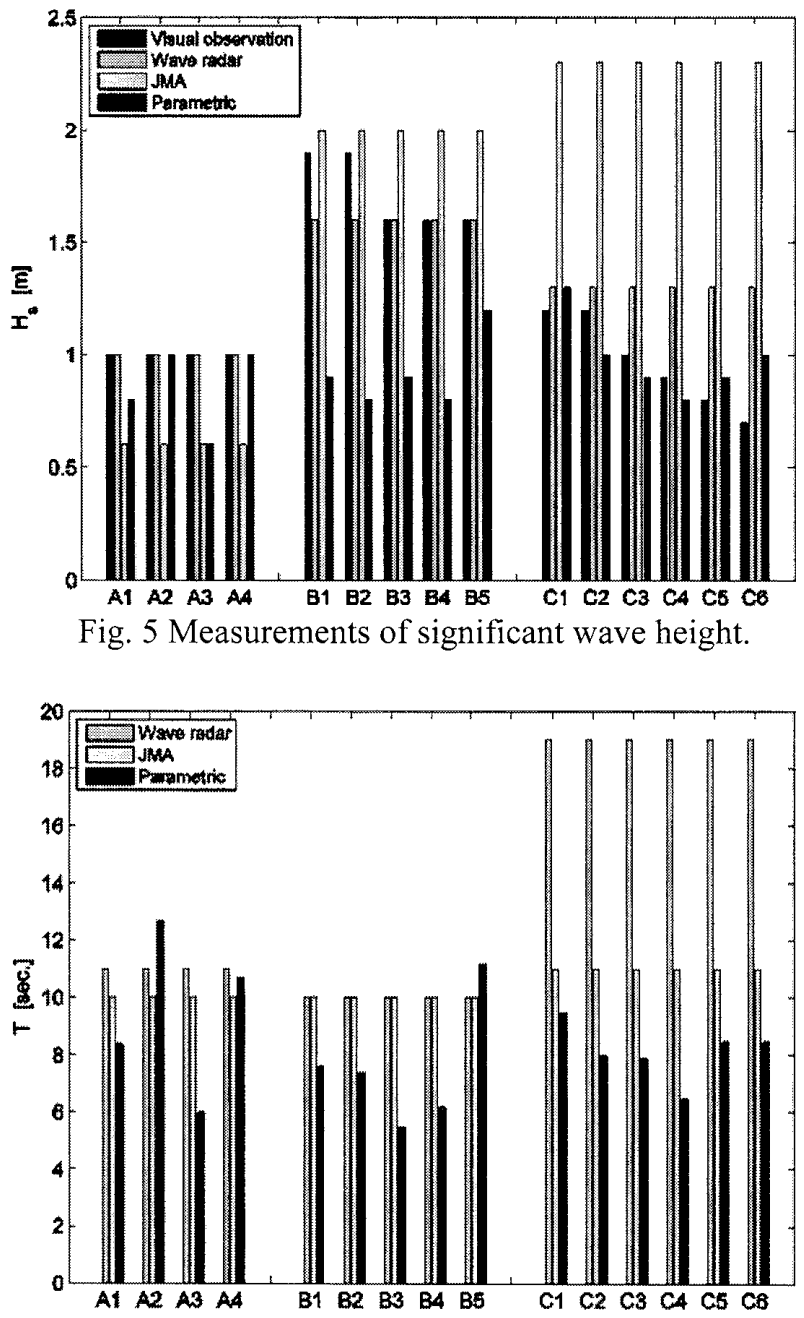

Fig. 6 Measurements of wave period.

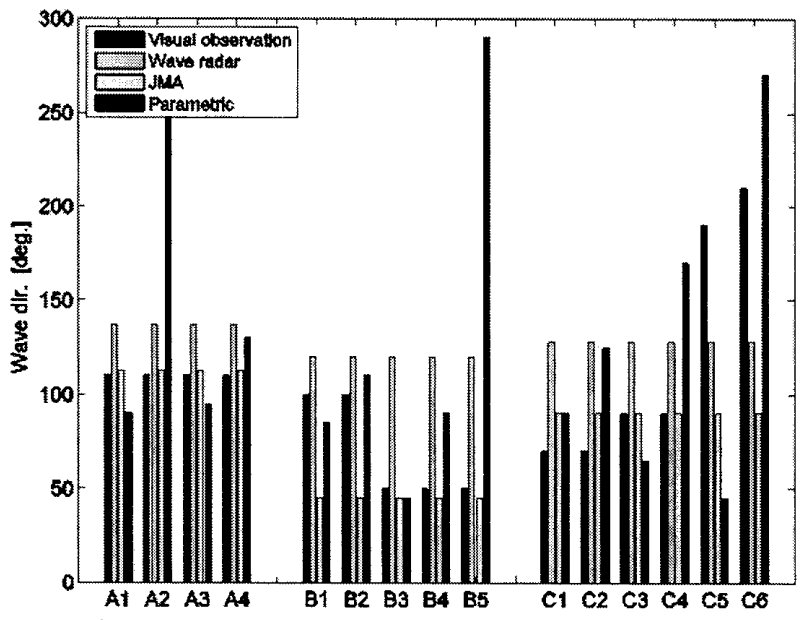

Fig. 7 Measurements of absolute wave direction.

mental sets for the wave radar monitoring system and for JMA.

\subsection{Discussion}

Considering the analysed point of JMA data does not coincide with the actual experimental area, the estimates of significant wave height by the parametric model compare reasonably well with two other sets of measurements in Figure 5. However, for the experi- 
mental sets $\mathrm{B} 1, \ldots, \mathrm{B} 5$ there is a tendency for the parametric model to give wave heights on the smaller side. It is difficult to explain exactly why this is so but the observation could relate to filtering, which is an inherent problem of the wave buoy analogy. Thus, it is in general possibly only to estimate those waves which are felt by the ship when the wave buoy analogy is applied for wave estimation. This phenomenon is discussed in rather details in the literatures ${ }^{(5,7,8)}$, but it should be noted that, typically, the phenomenon is most pronounced for larger sized vessels. Another interesting observation that can be made from Figure 5 is that the visual observations confirm the parametric model in the reducing trend of the wave height experienced in experimental sets $\mathrm{C} 1, \ldots, \mathrm{C} 6$ while constant differences can be seen in data sets $\mathrm{A} 1, \ldots \mathrm{A} 4$ and B1,...B5.

The agreement between the measurements of the wave period and the corresponding estimates by the parametric model is considered fair. It is not known why the wave radar monitoring system gives a wave period which is far from the results by JMA and the parametric model for data sets $\mathrm{C} 1, \ldots, \mathrm{C} 6$. Similar to the other two wave parameters, Figure 7 shows that the wave direction obtained by the parametric model, on average, agrees reasonably well with the other three sets of measurements. However, there are two solitary outliers of the parametric model when focus is turned to sets $\mathrm{A} 2$ and $\mathrm{B} 5$. The reason for these two outliers is that the parametric model estimates an "extra" second peak in the wave spectrum in these two cases. The consequence is a bimodal wave spectrum, where only the one peak should be considered as a part of the true spectrum. As a direct extension of this discussion it should be noted that although mixed-sea conditions can be estimated by the parametric model, the present analysis lacks a detailed study of the agreement of the actual distribution of wave energy with frequency and direction. This choice has been made partly due to space limitations and partly because the information is not available for the other three sets of measurements. However, not only integrated wave parameters but the complete distribution of wave energy must be correct for decision support systems to give reliable guidance with respect to critical wave-induced events. In the future, it could therefore be interesting to conduct a more comprehensive study of the considered data with respect to the distribution of wave spectral energy.

\subsection{Comparison with Bayesian estimation}

The wave buoy analogy builds typically on either parametric wave estimation, as described in this paper, or Bayesian wave estimation ${ }^{(2,3,5,9,10)}$. The main difference between the two concepts lies in the approach used to handle the minimization related to Eq. (2), leaving out further details.

The outcome of the parametric and Bayesian wave estimation for the studied data is summarized in Table 4. As the table shows, the two estimation concepts give not identical results when integrated wave parameters (wave direction, wave period, wave height) are compared. The comparison is visualized graphically by the plot in Figure 8 . The plot shows normalized wave parameters obtained by the parametric approach on the $\mathrm{x}$-axis and corresponding parameters obtained by the Bayesian approach on the y-axis. Each wave parameter (wave direction, wave period, wave height) has been normalized with the maximum value of the specific parameter obtained from either of the approaches.

From the plot in Figure 8 it appears evidently that the Bayesian estimation provides the largest wave height in all cases. The situation is almost opposite when the wave period is considered, since the parametric approach gives higher values in nearly all cases. The reason for this to be so is because the Bayesian approach solves the equation system, Eq. (2), discretely (frequency-wise and directional-wise) which means

Table 4 Wave parameters by parametric and Bayesian wave estimation.

\begin{tabular}{|c|c|c|c|c|c|c|}
\hline \multirow{2}{*}{$\begin{array}{l}\text { Run } \\
\text { ID }\end{array}$} & $\begin{array}{c}\text { Wave dir. } \\
\text { [deg.] }\end{array}$ & $\begin{array}{c}\text { Wave period } \\
\text { [sec.] }\end{array}$ & \multicolumn{2}{c|}{$\begin{array}{c}\text { Wave height } \\
{[\mathrm{m}]}\end{array}$} \\
\cline { 2 - 7 } & Param & Bay & Param & Bay & Param & Bay \\
\hline \multicolumn{7}{|c|}{$(2007 / 07 / 25)$} \\
\hline A1 & 90 & 110 & 8.4 & 10 & 0.8 & 0.9 \\
\hline A2 & 265 & 85 & 13 & 3.3 & 1.0 & 1.5 \\
\hline A3 & 95 & 110 & 6.0 & 10 & 0.6 & 1.0 \\
\hline A4 & 130 & 100 & 11 & 3.8 & 1.0 & 1.3 \\
\hline \multicolumn{7}{|c|}{$(2008 / 01 / 23)$} \\
\hline B1 & 85 & 115 & 7.6 & 5.9 & 0.9 & 1.2 \\
\hline B2 & 110 & 60 & 7.4 & 4.7 & 0.8 & 1.9 \\
\hline B3 & 45 & 115 & 5.5 & 4.7 & 0.9 & 2.2 \\
\hline B4 & 90 & 255 & 6.2 & 4.1 & 0.8 & 2.6 \\
\hline B5 & 290 & 120 & 11 & 5.6 & 1.2 & 2.0 \\
\hline \multicolumn{7}{|c|}{$(2009 / 03 / 11)$} \\
\hline C1 & 90 & 125 & 10 & 7.0 & 1.3 & 1.8 \\
\hline C2 & 125 & 95 & 8.0 & 7.9 & 1.0 & 2.6 \\
\hline C3 & 65 & 155 & 7.9 & 6.0 & 0.9 & 1.6 \\
\hline C4 & 170 & 80 & 6.5 & 4.8 & 0.8 & 2.7 \\
\hline C5 & 45 & 170 & 8.5 & 6.0 & 0.9 & 1.8 \\
\hline C6 & 270 & 106 & 8.5 & 4.5 & 1.0 & 2.3 \\
\hline
\end{tabular}




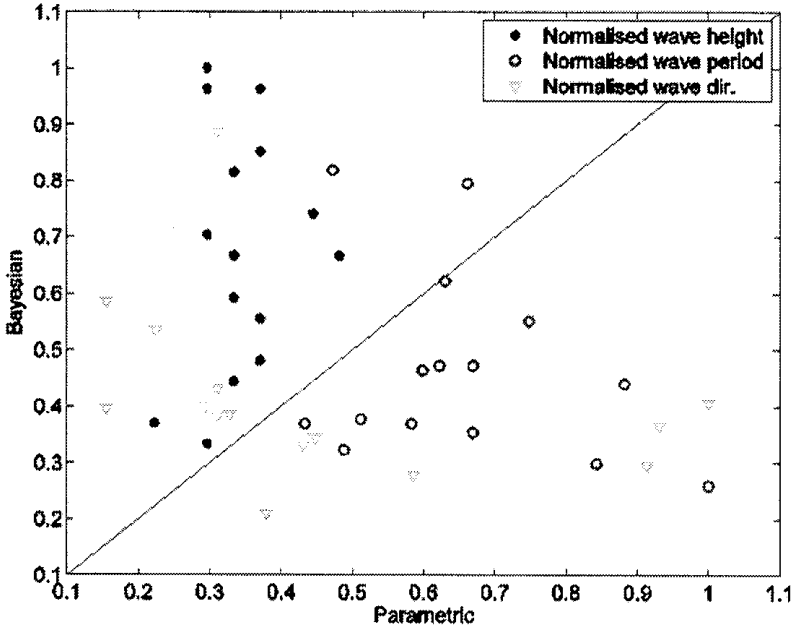

Fig. 8 Normalized wave parameters obtained by parametric versus Bayesian wave estimation. Normalization made with maximum value of the specific parameter.

that it is easier to fulfil the requirement with respect to conservation of energy compared to what the situation for the parametric estimation is, where the shape of the spectrum is given by definition. On the other hand, the "discrete solution" by the Bayesian estimation leads sometimes to shapes of wave spectra which have little resemblance to (true) physically observed ones. The consequence is that the frequency-wise distribution of energy in the Bayesian estimation takes unrestrained shape, and this can be considered as one of the reason why the Bayesian approach gives wave periods on the lower side as can be seen from Figure 8 . There can be made no general notes on the estimation of wave direction by the two estimation concepts. Thus, it is seen by the plot in Figure 8 that the points corresponding to estimates of the wave direction spread arbitrarily. This latter observation agrees well with the fact that the frequency-wise distribution of energy, discussed above, does not have an influence on the wave direction.

\section{Conclusions}

In the paper, parametric wave estimation was discussed as one of the practical methods to obtain sea state parameters from an advancing ship by using the wave buoy analogy. As part of the analysis of fullscale motion measurements from the T.S. Shioji-maru, comparisons with integrated wave parameters were made with other wave measurements based on visual observations, a wave radar monitoring system, and analyses carried out by Japan Meteorological Agency.
The paper contained also results derived from Bayesian wave estimation, which is a similar estimation concept that can be applied in the wave buoy analogy. All together the following conclusions can be drawn:

(1) The agreement between estimates of wave parameters by the parametric approach and by other measurements is reasonable.

(2) Detailed comparisons of the frequencydirectional distribution of energy have not been shown; for operator guidance the complete energy distribution is often necessary. This type of comparison could therefore be interesting to perform in the future.

(3) Parametric and Bayesian wave estimation gave not identical results. The explanation for this is due to the handling of the minimization problem, which is established as the governing equation system in the wave buoy analogy.

\section{Acknowledgements}

This work is partly supported by the invitation fellowship program for research of the Japan Society for the Promotion of Science (S11175). The measurement of the wave monitoring radar system at Nojima lighthouse was fully supported by the Third Regional Japan Coast Guard Headquarters and Japan Radio Co.,Ltd. The authors express sincere gratitude to the above organizations.

\section{References}

(1) Hansen, S.V. and Lützen, M.: Performance Monitoring and Ship Modelling by the Bond Graph Method, Proc. $11^{\text {th }}$ PRADS, Rio de Janeiro, Brazil, pp. 734-743, 2010.

(2) Iseki, T. and Ohtsu, K.: Bayesian estimation of directional wave spectra based on ship motions, Control Engineering Practice, Vol. 12, pp. 25-30, 2000.

(3)Nielsen, U.D.: Estimations of on-site directional wave spectra from measured ship responses, Marine Structures, Vol. 19, pp. 33-69, 2006.

(4) Nielsen, U.D.: Introducing two hyperparameters in Bayesian estimation of wave spectra, Probabilistic Engineering Mechanics, Vol. 23, pp. 84-94, 2008.

(5)Pascoal, R., Guedes Soares, C. and Sørensen, A.J. Ocean wave spectral estimation using vessel wave frequency motions, Journal of Offshore Mechanics and Arctic Engineering, Vol. 129, pp. 90-96, 2007. 
(6)Tannuri, E.A., Sparano, J.V., Simos, A.N. and Da Cruz, J.J.: Estimating directional wave spectrum based on stationary ship motion measurements, Applied Ocean Research, Vol. 25, pp. 243-261, 2003.

(7) Nielsen, U.D.: Response-based estimation of sea state parameters - influence of filtering, Ocean Engineering, Vol. 34, pp. 1797-1810, 2007.

(8) Simos, A.N., Tannuri, E.A., Sparano, J.V., and Matos, V.L.F.: Estimating wave spectra from the motions of moored vessels: Experimental validation, Applied Ocean Research, Vol. 32, pp. 191-208, 2010.

(9) Iseki, T. and Terada, D.: Bayesian Estimation of Directional Wave Spectra for Ship Guidance Systems, International Journal of Offshore and Polar Engineering, Vol 12, pp 25-30, 2002.

(10)Nielsen, U.D. and Iseki, T.: Estimation of Sea State Parameters from Measured Ship Responses The Bayesian Approach with Fixed Hyperparameters, Proc. OMAE2010, Shanghai, China, DVD pp.1-10, 2010.

\section{Questions and answers}

Hiroshi Ishida (Kobe University):
It is assumed that there is a linear relationship between ship's motion and ocean waves. But it seems the relationship depends on the conditions of ocean waves and the characteristics of ship's motion. That is, it seems both have a non-linear relationship under some wave conditions. The observations were made on the relatively low seas, where the wave height was from one to two meters. It seems the wave height is lower than that which ship's motion and the wave condition have a linear relationship. Is it possible to apply your method to estimate the wave condition in such a low wave condition?

\section{Ulrik Dam NIELSEN:}

It is the authors' opinion that the wave heights are not small but good enough for the linear relationship. Theoretical calculations of transfer functions of T.S. Shioji-maru have been compared with experiments with good agreement (Figure 9). In the experiments, an 1/17 model ship was used and the wave heights were set from $1.6 \mathrm{~cm}$ to $2.8 \mathrm{~cm}$ to keep the wave slope constant. The wave heights correspond to about $1 \mathrm{~m}$ in the full scale. The graphs show that the linear assumption is quite reasonable. The authors believe that the methods can be applied to the wave conditions described in the paper.
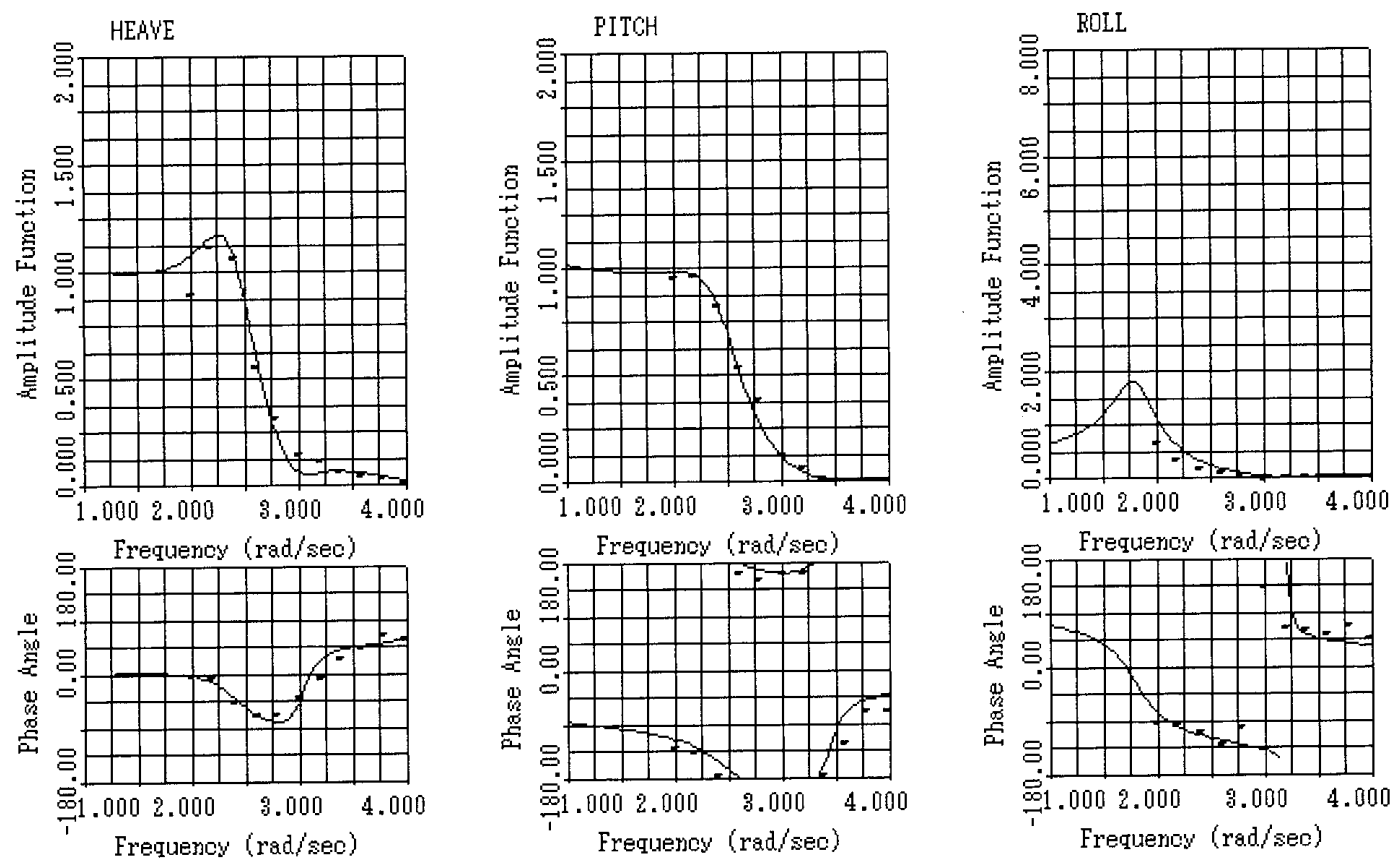

Fig. 9 Comparisons of transfer functions of heaving, pitching and rolling. The lines and markers denote the results of calculations and experiments. (Encounter angle $=150 \mathrm{deg}$, Froude No. $=0.2$ ) 